\title{
Treating primary hypothyroidism with weekly doses of levothyroxine: a randomized, single-blind, crossover study
}

\author{
Tratamento de hipotiroidismo primário com doses semanais \\ de levotiroxina: um estudo randomizado, unicego, crossover
}

Andressa Bornschein', Gilberto Paz-Filho², Hans Graf', Gisah A. de Carvalho'

${ }^{1}$ Serviço de Endocrinologia e Metabologia, Hospital de Clínicas, Universidade Federal do Paraná (SEMPR/HCUFPR), Curitiba, PR, Brazil ${ }^{2}$ The John Curtin School of Medical Research, Australian National University, Canberra, ACT, Australia
Correspondence to: Gisah A. de Carvalho Av. Agostinho Leão Junior, 285 80030-110 - Curitiba, PR, Brazil Carvalho.gisah@gmail.com

Received on Dec/16/2011 Accepted on Mar/22/2012

\begin{abstract}
Objective: Compliance to levothyroxine treatment in hypothyroidism is compromised by daily schedule, and a weekly dose may be an alternative. Subjects and methods: This was a randomized, crossover study. Fourteen females were assigned to daily or weekly doses of LT4. After six weeks, they switched regimens. Thyroid parameters were measured at baseline, and after 42 and 84 days. Echocardiogram and hyperthyroidism symptoms were evaluated before and four hours after LT4 intake. Results: In the weekly dose treatment, fT4 levels were higher after taking LT4, and lower seven days after the last dose; by the $6^{\text {th }}$ week there was a small decrease in T3 levels. TSH remained unchanged and there were no hyperthyroidism symptoms or echocardiographic manifestations. Conclusion: Weekly dose leads to transient increases in fT4, without hyperthyroidism or cardiac symptoms. That approach seems to be a safe alternative for the treatment of hypothyroidism. Arq Bras Endocrinol Metab. 2012;56(4):250-8
\end{abstract}

\section{Keywords}

Adhesion; dosing; thyroid; treatment

\section{RESUMO}

Objetivo: Aderência ao tratamento do hipotiroidismo é comprometido pelo uso diário de levotiroxina, e doses semanais poderiam ser uma alternativa. Sujeitos e métodos: Este é um estudo randomizado, crossover. Quatorze mulheres foram selecionadas para receber LT4 diariamente ou semanalmente. Após seis semanas, houve inversão do regime de tratamento. Avaliações tireoideanas foram realizadas antes, após 42 e 84 dias. Avaliação de sintomas de hipertireoidismo e ecocardiograma foi realizada antes e após quatro horas de LT4. Resultados: Com dose semanal, os níveis de fT4 foram mais elevados logo após a dose de LT4, e menores após sete dias; após seis semanas, houve diminuição de T3. TSH permaneceu inalterado e não houve manifestações ecocardiográficas ou de hipertireodismo. Conclusão: Dose semanal de LT4 leva à elevação de fT4, sem manifestações de hipertireoidismo, e parece ser uma alternativa segura para o tratamento do hipotireoidismo. Arq Bras Endocrinol Metab. 2012;56(4):250-8

Descritores

Adesão; dose; tireoide; tratamento

\section{INTRODUCTION}

$\mathrm{H}$ ypothyroidism is the most common thyroid disorder, affects women more frequently, and incidence increases with age. Its clinical presentation ranges from asymptomatic to severe, with myxedema coma as a severe complication $(1,2)$.

In spite of being easily treatable using a daily dose of levothyroxine (LT4), many patients remain hypothy- 
roid due to malabsorption syndromes, pancreatic and liver disorders, drug interactions, autoimmune gastritis, polymorphisms in type 2 deiodinase, high fiber diet and, more frequently, non-compliance to LT4 therapy. Many studies have shown that up to $40 \%$ of patients are undertreated, and also up to $40 \%$ may be overtreated, especially in the elderly (1-6). A study evaluating 339 hypothyroid patients aged 65 and over showed that more than $40 \%$ had low and $16 \%$ had high TSH levels, possibly correlated with lower weight (6).

An interesting study performed in Brazil involving decompensated hypothyroid patients showed that more than $80 \%$ of the subjects said they did not follow physician instructions due to prescription misunderstanding or forgetfulness (3). Non-compliance is attributed to the limitations and inconveniences imposed by therapy: 1) the need to take the medication while fasting; 2) the need to wait approximately 30 minutes for the next meal; 3) the need to take the medication on a daily basis; and 4) the need to avoid other medications that may interfere with absorption, such as ferrous sulfate, calcium carbonate, bile acid sequestrants, aluminum hydroxide antacids, sucralfate, sodium polystyrene sulfonate and raloxifene. Moreover, other drugs may interfere with LT4 metabolism, such as the anticonvulsants carbamazepine, phenytoin, and phenobarbital $(7,8)$.

In adults, non-compliance can lead to metabolic and cardiovascular risk disturbances, as observed in classic hypothyroidism, such as increased levels of serum C-reactive protein (CRP), Lipoprotein "a" [Lp(a)], total cholesterol (TC), and low density lipoprotein cholesterol (LDL-C) $(9,10)$. Cardiovascular system alterations are not uncommon and include decreased output, increased peripheral resistance and reduced blood volume, leading to pulse pressure narrowing, increased circulation time, and decreased blood flow to the tissues, which can be well exemplified by the coolness and pallor of the skin (11). Affective disorders, such as paranoid and depressive behavior and impairment of quality of life, may also be found $(12,13)$.

Many attempts to improve therapy compliance in chronic diseases have been unsuccessful. Specifically in the case of hypothyroidism, new therapeutic alternatives have been suggested; weekly and intermittent administration of LT4 is one of them (14-22).

A study conducted by Bach-Huynh and cols. (14), evaluating alternative schedules for LT4 dosing, showed that administration while fasting remains the best option. Nevertheless, bedtime or breakfast schedules also showed satisfactory results and could be attempted in non-compliant patients.

Some recent series evaluating hypothyroid patients with poor control have shown that adequate thyroid hormone levels were obtained after introducing weekly LT4 $(17,19,20,22)$. However, cardiovascular side effects were not thoroughly investigated in these reports.

The half-life of endogenous thyroxine is approximately seven days, but its biological activity may be sustained for a longer period. Given orally, the effects of LT4 are observed within three to five days, with a half-life that varies according to the thyroid state: nine to ten days for hypothyroid, six to seven days for euthyroid and three to four days for hyperthyroid patients $(23,24)$. Given this prolonged half-life, it is feasible to hypothesize that LT4 given in higher doses and at longer intervals may be a feasible approach for treating hypothyroid patients. This could increase compliance, without compromising hormonal balance. The LT4 dose to be used in these situations remains a dilemma. Grebe and cols. (16), in their evaluation, used a 7 -fold higher dose, with satisfactory results. Rivkees and cols. (25) used a small LT4 dose in an 11-month old child, without initial adequate effects on thyroid hormones levels, but reaching satisfactory thyroid hormones levels after correcting the dose by weight. In another study (19), it was also necessary to increase the dose for adequate control. It seems that the most adequate weekly dose is 7 -fold higher than the daily one. However, higher doses of LT4 could lead to intermittent iatrogenic hyperthyroidism (26).

The heart is the main organ affected by hyperthyroidism, which could lead to the development of arrhythmias, decrease in cardiac output and contractility, changes in blood pressure, valvular regurgitation, and increase in heart size $(27,28)$. The only randomized crossover study showed that weekly administration of LT4 was well-tolerated, without evidence of treatment toxicity, including cardiac effects (16). In this new randomized study, we sought to evaluate the safety and efficacy of a weekly dose regimen of LT4 in hypothyroid patients, with a more comprehensive description of the cardiac effects.

\section{SUBJECTS AND METHODS}

\section{Patients}

Fourteen females (mean age $41.8 \pm 4.8$ years old) were recruited from the thyroid outpatient clinic of 
the Hospital de Clínicas da Universidade Federal do Paraná, Curitiba, Brazil. All patients had primary hypothyroidism (eleven patients with hypothyroidism caused by Hashimoto's thyroiditis, two with hypothyroidism after surgery to treat multinodular goiter, and one with hypothyroidism after radioactive ablation for Graves' disease). Only euthyroid patients under treatment with daily stable LT4 doses (mean dose $79.5 \pm 28.9 \mu \mathrm{g} /$ day) and TSH and free T4 (fT4) levels within normal range in the previous three months were recruited. None had coronary diseases, arrhythmias, malabsorptive disorders, or severe systemic illnesses. In addition, we excluded patients with concomitant use of drugs that have been shown to interfere with LT4 absorption $(7,8)$.

\section{Methods}

This was a randomized, crossover study. It was also single-blinded, since the two physicians who performed the echocardiogram were not aware of treatment status.

Patients were randomized in two groups. On day 0 (D0), participants in group $\mathrm{l}(\mathrm{Gl}, \mathrm{n}=8)$ were advised to keep the usual daily dose of LT4. In group 2 (G2, $\mathrm{n}=6$ ), patients were advised to stop their usual daily dose and start taking a weekly dose of LT4, seven times higher than their usual dose. In both groups, LT4 brand was not changed. All patients maintained this treatment for six weeks. In the seventh week (day 42), patients were advised to shift their therapeutic regimen: patients in Gl started taking LT4 once a week, in a dose seven times higher than usual; patients in G2 were advised to go back to taking LT4 every day, in their usual dose. This treatment was maintained for other six weeks. Consequently, the study lasted 12 weeks, ending on day 84 . Doses were not altered during the daily or weekly therapeutic regimens.

On day 0 (D0), 24 hours after their last dose of LT4, all patients were submitted to blood testing. On day 42 (D42), Gl patients had received their last dose of LT4 on the previous day (D41), while for G2 patients, it had been 7 days earlier. On day 84 (D84), Gl patients had received their last dose 7 days earlier and G2 patients, the day before (D83).

On D0 and D42, after blood testing, patients received LT4; 60 minutes afterwards, breakfast was offered. New blood samples were drawn 2 and 4 hours after the administration of LT4 on those days. On D84, only fasting blood samples were obtained. Doppler echocardiograms were performed before and 4 hours after LT4 administration, on days 0 and 42. TSH (Thyroid Stimulating Hormone - Abbott Diagnostics, Abbott Park, IL, reference values 0.49-4.67 mU/L); fT4 (free Thyroxine - Abbott Diagnostics, reference values 0.71$1.85 \mathrm{ng} / \mathrm{dL}$, sensitivity $0.40 \mathrm{ng} / \mathrm{dL}, \mathrm{CV} \leq 10 \%)$; and TT3 (Total Triiodothyronine - microparticle enzyme immunoassay, AxSYM T3, Abbott Diagnostics, reference values 79.0-149.0 ng/dL, sensitivity $30.0 \mathrm{ng} / \mathrm{dL}$, $\mathrm{CV} \leq 16 \%$ ) were measured on days 0,42 and 84 , before LT4 administration; fT4 and TT3 (but not TSH) were also measured 2 and 4 hours after LT4 administration. Transthoracic Doppler echocardiogram was performed with a dual M-mode system (HP 77020AC, Hewlett Packard, Andover, Massachusetts, USA). Uni- and bidimensional measurements were obtained by two blinded investigators. The subsequent exams were repeated by the same investigator, for each patient they had previously examined. Systolic function was analyzed by the following variables: pre-ejection period (PEP), aortic ejection time (ET), isovolumetric contraction time (ICT), and heart rate (HR). The study design is illustrated in figure 1.

Clinical changes were evaluated by the hyperthyroidism symptom scale (HSS) (29) at baseline as well as 4 hours after LT4. Results were expressed as mean \pm SD or median (range). The Kolmogorov-Smirnov test was used to assess normality of distributions. Groups were compared by ANOVA for repeated measures or by Kruskal-Wallis test. The time effect was analyzed by Student's paired t-test or Wilcoxon test, accordingly. Two-sided tests were used with $\mathrm{P}<0.05$ being considered significant. Analyses were performed using SPSS software, Version 15 (SPSS Inc., Chicago, IL, USA).

The study was reviewed and approved by the Ethics Committee of the Hospital de Clínicas da Universidade Federal do Paraná, and written informed consent was obtained from all patients.

\section{RESULTS}

\section{Baseline characteristics}

Eight patients were randomized to group 1 and six, to group 2. There were no statistical differences between the groups regarding age, thyroid hormone levels, and echocardiographic parameters (Table 1). 


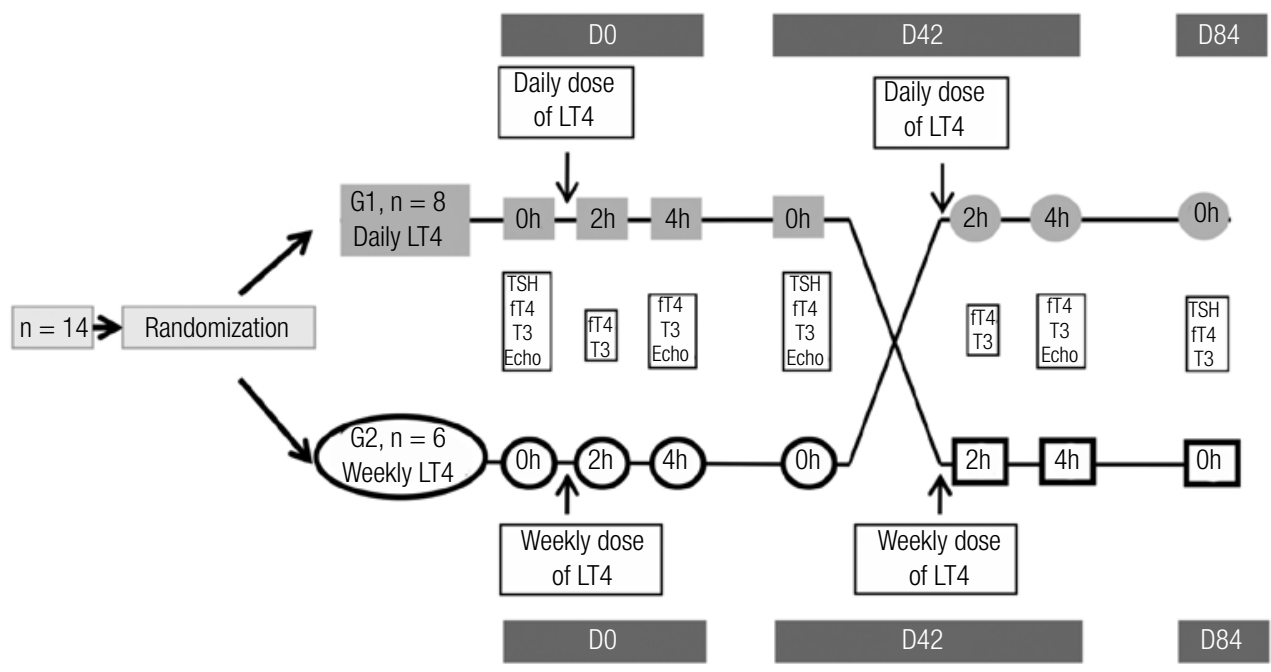

D0, D42 and D84: day 0, 42 and 84; Echo: echocardiogram; fT4: free thyroxine; LT4: levothyroxine. Squares: patients of group 1; circles: patients of group 2.

Figure 1. Study design.

Table 1. Baseline characteristics in the study groups

\begin{tabular}{lccc}
\hline & G1 & G2 & p value \\
\hline Age & $41.2 \pm 8.41$ & $42.5 \pm 7.48$ & 0.95 \\
LT4 dose & $1.11 \pm 0.14$ & $1.22 \pm 0.08$ & 0.27 \\
& $(1.02-1.20)$ & $(1.16-1.28)$ & \\
TSH & $2.39 \pm 1.19$ & $2.38 \pm 1.37$ & 0.99 \\
& $(1.57-3.21)$ & $(1.29-3.47)$ & \\
fT4 & $1.12 \pm 0.17$ & $1.13 \pm 0.15$ & 0.92 \\
& $(1.01-1.23)$ & $(1.01-1.25)$ & \\
TT3 & $94.9 \pm 6.2$ & $93.7 \pm 14.6$ & 0.88 \\
& $(82.8-107.2)$ & $(82.0-105.4)$ & \\
PEP & $90.0 \pm 16.0$ & $91.6 \pm 9.8$ & 0.82 \\
& $(79.9-101.1)$ & $(83.7-99.5)$ & \\
AET & $315.0 \pm 20.7$ & $320.0 \pm 29.6$ & 0.71 \\
& $(300-329.3)$ & $(196.6-343.7)$ & \\
ICT & $55.0 \pm 13.3$ & $75.0 \pm 29.6$ & 0.11 \\
& $(45.7-64.4)$ & $(51.4-98.6)$ & \\
PEP/AET & $0.292 \pm 0.05$ & $0.286 \pm 0.04$ & 0.96 \\
& $(0.258-0.326)$ & $(0.285-0.289)$ & \\
HR & $79.2 \pm 11.1$ & $87.5 \pm 7.3$ & 0.14 \\
& $(71.5-86.9)$ & $(81.7-93.3)$ & \\
\hline
\end{tabular}

Values shown as means \pm SD (confidence interval); NS: not significant; LT4: levothyroxine dose $(\mu \mathrm{g} / \mathrm{kg} / \mathrm{day}) ;$ TSH: thyroid stimulating hormone (mU/L); fT4: free thyroxine (ng/dL); TT3: total triiodothyronine (ng/dL); AET: aortic ejection time (ms); ICT: isovolumetric contraction time (ms); AET/PEP - relation between aortic ejection time and pre-ejection period; HR: heart rate (beats per minute).

\section{Changes in thyroid hormones - G1}

Fasting TSH levels were not significantly different while on daily $(2.39 \pm 1.19 \mathrm{mU} / \mathrm{L}$ on D0 $)$ or weekly
$(2.03 \pm 1.40 \mathrm{mU} / \mathrm{L}$ on $\mathrm{D} 42)$ regimens $\left(\mathrm{p}>0.05 ; \mathrm{Fi}^{-}\right.$ gure 2). Fasting fT4 levels were $1.12 \pm 0.17 \mathrm{ng} / \mathrm{dL}$ for the daily and $1.22 \pm 0.45$ for the weekly schedule. Peak levels of fT4 were greater 2 hours after taking a weekly dose of LT4 $(1.91 \pm 0.42 \mathrm{ng} / \mathrm{dL})$, as opposed to peak levels that were observed 2 hours after taking the daily dose $(1.19 \pm 0.26 \mathrm{ng} / \mathrm{dL} ; \mathrm{p}=0.0006)$. Similarly, peak levels of fT4 were greater 4 hours after taking the weekly dose of LT4 $(1.78 \pm 0.35 \mathrm{ng} / \mathrm{dL})$, as opposed to peak levels that were observed 4 hours after taking the daily dose $(1.16 \pm 0.24 \mathrm{ng} / \mathrm{dL} ; \mathrm{p}=$ 0.001; Figure 3).

While fasting, TT3 levels were similar on D0 before taking the daily $(94.9 \pm 17.59 \mathrm{ng} / \mathrm{dL})$ or the weekly dose of LT4 $(97.3 \pm 12.79 \mathrm{ng} / \mathrm{dL})$ on D42 $(\mathrm{p}>0.05)$. Peak levels of TT3 were similar 2 hours after taking the daily $(93.4 \pm 18.04 \mathrm{ng} / \mathrm{dL})$ or the weekly dose of LT4 $(92.6 \pm 12.91 \mathrm{ng} / \mathrm{dL} ; \mathrm{p}>0.05)$. Likewise, peak levels of TT3 were similar 4 hours after taking the daily (93.6 $\pm 20.38 \mathrm{ng} / \mathrm{dL})$ or the weekly dose of LT4 (93.9 \pm $11.12 \mathrm{ng} / \mathrm{dL} ; \mathrm{p}>0.05$; Figure 4).

After 6 weeks of each treatment, fT4 and TT3 levels dropped while on the weekly regimen. Before starting treatment, fT4 values were $1.22 \pm 0.45 \mathrm{ng} / \mathrm{dL}$, dropping to $0.92 \pm 0.22 \mathrm{ng} / \mathrm{dL}(\mathrm{p}=0.036)$. TT3 levels also decreased from $97.3 \pm 12.79 \mathrm{ng} / \mathrm{dL}$ to $84.8 \pm 14.07$ $\mathrm{ng} / \mathrm{dL}$, when comparing the moment before weekly 
treatment and after 6 weeks of treatment $(\mathrm{p}>0.05)$. At the same time, but while on daily doses, there were slight increases in FT4 and TT3 ( $p>0.05)$. Comparing daily and weekly regimens, fT4 values were higher on daily than on weekly regimen $(1.22 \pm 0.17$ vs. $0.92 \pm$ $0.22, \mathrm{p}=0.036)$, and TT3 levels were also higher after 6 weeks under daily treatment $(97.3 \pm 12.79$ vs. 84.81 $\pm 14.07, \mathrm{p}>0.05$; Figures 3 and 4 ).

\section{Changes in thyroid hormones - G2}

While fasting, TSH levels on D0 were not significantly different while on weekly $(2.38 \pm 1.37 \mathrm{mU} / \mathrm{L})$ or daily LT4 $(3.32 \pm 3.10 \mathrm{mU} / \mathrm{L})$ on D42 ( $>0.05$; Figure 2$)$. Similarly, while fasting, fT4 levels were not significantly different while on the weekly $(1.13 \pm 0.15 \mathrm{ng} / \mathrm{dL})$, or daily regimen $(1.04 \pm 0.45 \mathrm{ng} / \mathrm{dL} ; \mathrm{p}>0.05)$. Peak levels of fT 4 were greater 2 hours after taking the weekly dose of LT4 $(1.91 \pm 0.66 \mathrm{ng} / \mathrm{dL})$, as opposed to peak levels that were observed 2 hours after taking the daily dose $(1.13 \pm 0.26 \mathrm{ng} / \mathrm{dL} ; \mathrm{p}=0.02)$. Similarly, peak levels of fT4 were greater 4 hours after taking a weekly dose of LT4 $(1.91 \pm 0.49 \mathrm{ng} / \mathrm{dL})$, as opposed to peak levels that were observed 4 hours after taking the daily dose $(1.13 \pm 0.25 \mathrm{ng} / \mathrm{dL} ; \mathrm{p}=0.006$; Figure 5$)$.

While fasting, TT3 levels were similar at all times: $93.7 \pm 14.65$ vs. $89.9 \pm 14.07 \mathrm{ng} / \mathrm{dL}$ on D0 and D42, weekly and daily, respectively $(\mathrm{p}>0.05)$. Peak levels of TT3 were similar 2 hours after taking the weekly $(88.9$ $\pm 8.47 \mathrm{ng} / \mathrm{dL})$ or the daily dose of LT4 $(78,7 \pm 12,88$ $\mathrm{ng} / \mathrm{dL} ; \mathrm{p}>0.05)$. Likewise, peak levels of TT3 were similar 4 hours after taking the weekly $(91.5 \pm 10.19$ $\mathrm{ng} / \mathrm{dL})$, or a daily dose of LT4 $(84.4 \pm 11.88 \mathrm{ng} / \mathrm{dL}$; $\mathrm{p}>0.05$; Figure 6 ).

Similar to what was seen in Gl, after 6 weeks of treatment, fT4 dropped from $1.04 \pm 0.45 \mathrm{ng} / \mathrm{dL}$ to $1.16 \pm 0.21 \mathrm{ng} / \mathrm{dL}$ while on the weekly regimen (comparing the values before starting the regimen and after 6 weeks of treatment, respectively), but no statistical significance was observed $(\mathrm{p}>0.05)$. The same changes were observed in TT3 profile, which dropped from $93.7 \pm 14.65 \mathrm{ng} / \mathrm{dL}$ to $89.8 \pm 14.07 \mathrm{ng} / \mathrm{dL}(\mathrm{p}$ $>0.05$ ). While on daily treatment, there was an increase in fT4 and TT3 levels ( $\mathrm{p}>0.05)$. When comparing the daily and the weekly values after 6 weeks, fT4 daily values were higher than weekly results $(1.16 \pm 0.21 \mathrm{vs}$. $1.04 \pm 0.45 \mathrm{ng} / \mathrm{dL}, \mathrm{p}>0.05)$, and TT3 daily values were also higher than weekly values $(95.1 \pm 15.59 \mathrm{vs}$. $89.8 \pm 14.07 \mathrm{ng} / \mathrm{dL}, \mathrm{p}>0.54$; Figures 5 and 6 ).
Changes in thyroid hormones - Daily versus Weekly Doses

On D0, while fasting, all patients were still taking LT4 daily, and there were no significant differences in TSH, fT4 and TT3 levels between both groups (Table 1). After taking LT4, fT4 was higher in patients taking the weekly dose, both two hours $(1.91 \pm 0.51 v s .1 .16 \pm 0.21 \mathrm{ng} / \mathrm{dL}$, $\mathrm{p}<0.01)$ and four hours after LT4 $(1.84 \pm 0.40$ vs. 1.15 $\pm 0.24 \mathrm{ng} / \mathrm{dL} ; \mathrm{p}<0.0 \mathrm{l})$. No significant differences were observed in TT3 levels after two hours $(87.1 \pm 17.21$ in daily and $91.02 \pm 11.00 \mathrm{ng} / \mathrm{dL}$ in weekly regimen, $\mathrm{p}>0.05)$, and after four hours of the LT4 dose $(89.8 \pm$ 17.33 in the daily and $92.9 \pm 10.40 \mathrm{ng} / \mathrm{dL}$ in the weekly dose, $\mathrm{p}>0.05$ ). After 6 weeks, fasting TSH levels of both groups were similar $(1.87 \pm 1.60$ and $3.45 \pm 2.67$ $\mathrm{mU} / \mathrm{L}, \mathrm{p}>0.05)$. At the same time, fT4 levels were higher in patients taking daily than in patients on weekly LT4 $(1.19 \pm 0.21$ vs. $0.97 \pm 2.50 \mathrm{ng} / \mathrm{dL}, \mathrm{p}<0.01)$, with no difference for TT3 $(96.4 \pm 13.5$ in the daily vs. $86.9 \pm$ $3.53 \mathrm{ng} / \mathrm{dL}$ in the weekly dose, $\mathrm{p}>0.05$ ).

\section{Changes in echocardiographic parameters}

At baseline (D0), before taking LT4, echocardiographic parameters were similar in both groups (Table 1). Four hours after LT4, those parameters were still comparable. Similar behavior was observed on D42: no differences were seen between groups, either before or four hours after taking LT4. When comparing the results before and four hours after LT4 within each group, all echocardiographic parameters were similar, both on days 0 and 42 (all $\mathrm{p}>0.05$; Table 2 ).

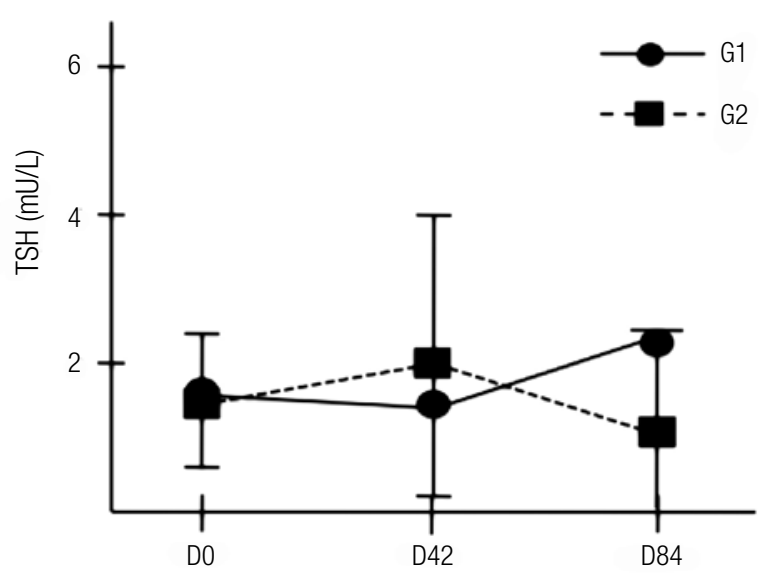

$p>0.05$ for all comparisons between groups and within the same group; Bars: means \pm SD.

Figure 2. Changes in serum TSH levels. 


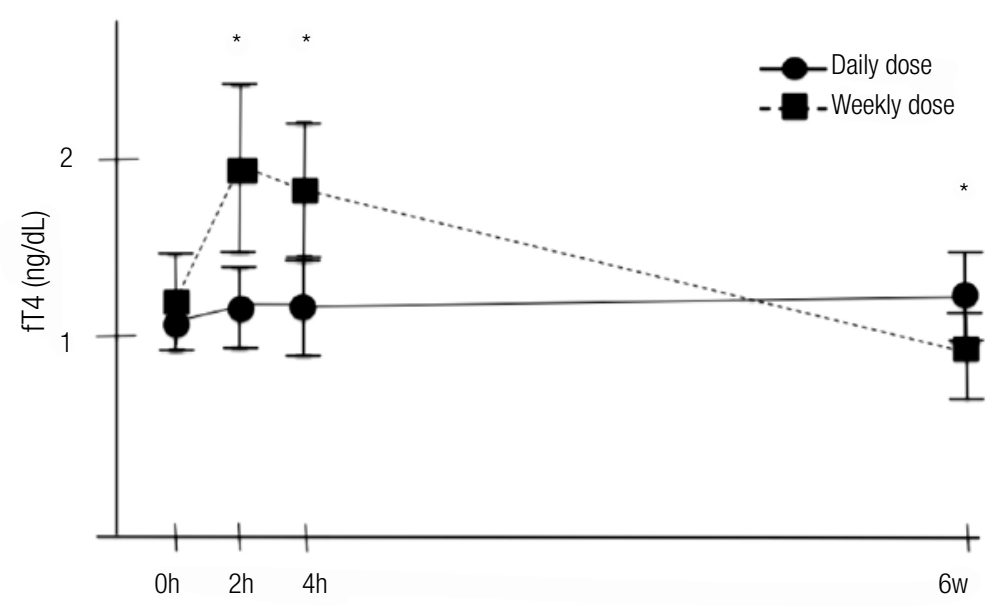

${ }^{*} \mathrm{p}<0.05$ for comparisons within the same group, daily vs. weekly; Bars: means \pm SD.

Oh, $2 \mathrm{~h}$ and 4h: before, after 2 and 4 hours of LT4; 6w: before LT4 on D42 for daily, and D84 for weekly dose.

Figure 3. Changes in serum fT4 levels in G1.

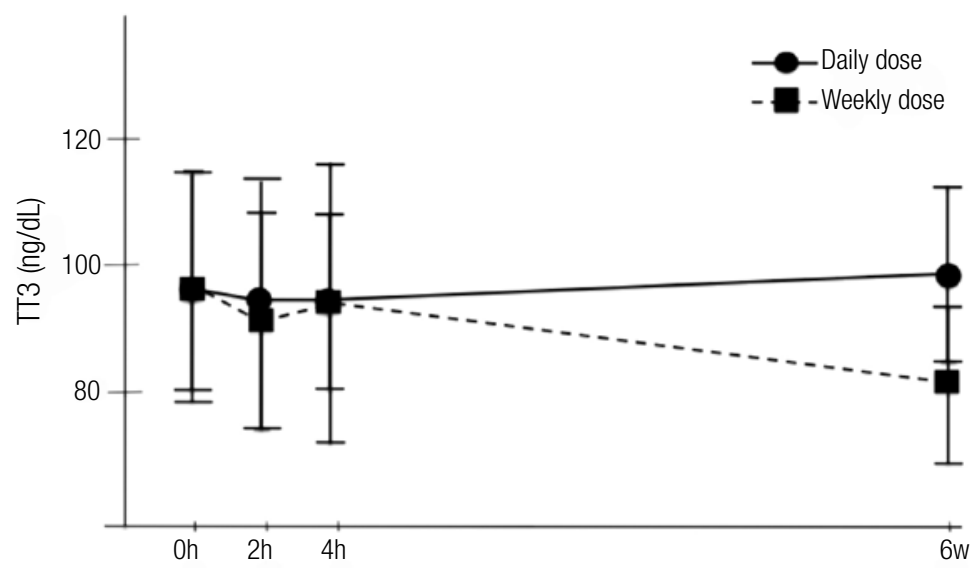

$p>0.05$ for all comparisons within the same group, daily vs. weekly; Bars: means $\pm S D$.

Oh, 2 h and 4 h: before, after 2 and 4 hours of LT4; 6w: before LT4 on D42 for daily, and D84 for weekly dose.

Figure 4. Changes in serum $T 33$ levels in G1.

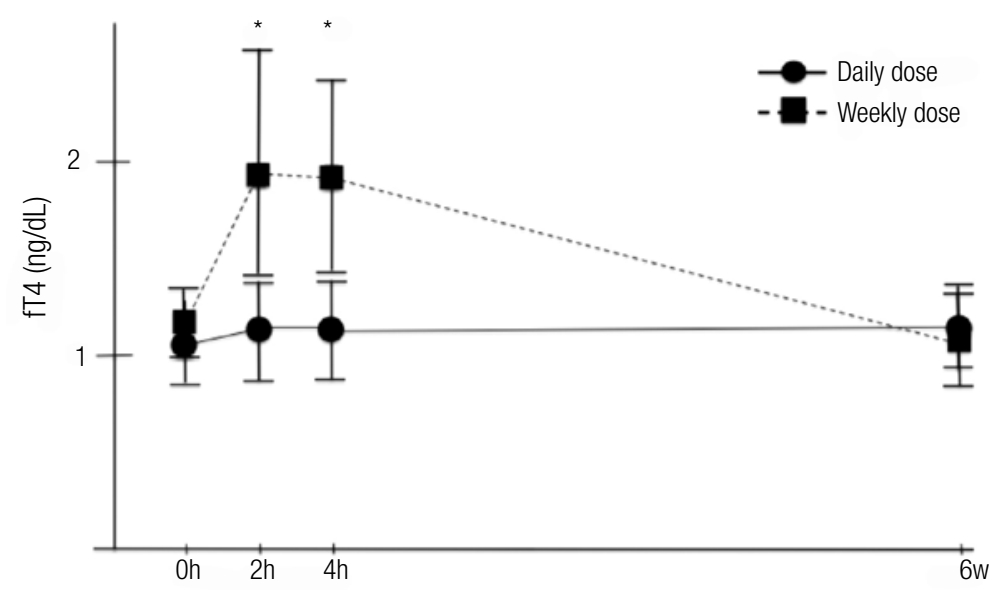

${ }^{*} \mathrm{p}<0.05$ for comparisons within the same group, daily vs. weekly; Bars: means \pm SD.

0h, $2 \mathrm{~h}$ and 4h: before, after 2 and 4 hours of LT4; 6w: before LT4 on D42 for weekly, and D84 for daily dose.

Figure 5. Changes in serum fT4 levels in G2. 


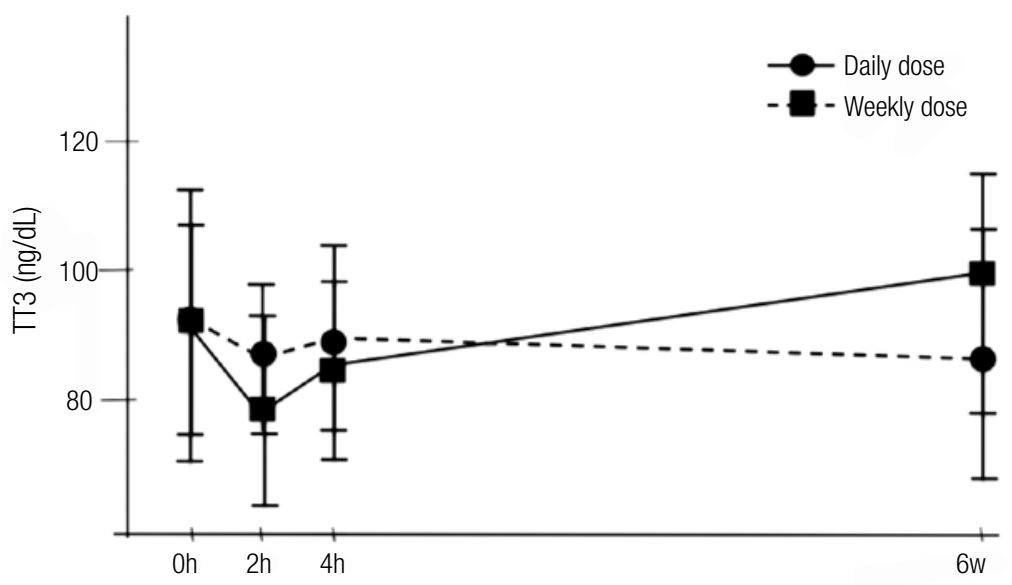

$p>0.05$ for all comparisons within the same group, daily vs. weekly; Bars: means \pm SD.

Oh, $2 \mathrm{~h}$ and $4 \mathrm{~h}$ : before, after 2 and 4 hours of LT4; 6w: before LT4 on D42 for weekly, and D84 for daily dose.

Figure 6. Changes in serum $\Pi 33$ levels in $\mathrm{G} 2$.

Table 2. Echocardiographic parameters in groups 1 and 2

\begin{tabular}{|c|c|c|c|c|c|c|c|}
\hline & & \multicolumn{3}{|c|}{ DO } & \multicolumn{3}{|c|}{ D42 } \\
\hline & & Fasting & 4 hours after LT4 & $p$ value & Fasting & 4 hours after LT4 & $p$ value \\
\hline \multirow[t]{4}{*}{ G1 } & AET & $315 \pm 20.70$ & $311 \pm 21.00$ & 0.28 & $299 \pm 37.41$ & $288.7 \pm 21.00$ & 0.76 \\
\hline & ICT & $55 \pm 14.39$ & $56.8 \pm 13.34$ & 0.50 & $53.1 \pm 13.34$ & $56.8 \pm 18.71$ & 0.19 \\
\hline & AET/PEP & $0.283 \pm 0.05$ & $0.280 \pm 0.07$ & 0.67 & $0.292 \pm 0.07$ & $0.288 \pm 0.07$ & 0.68 \\
\hline & $\mathrm{HR}$ & $79.25 \pm 11.10$ & $80.1 \pm 8.30$ & 0.75 & $76 \pm 9.60$ & $78.2 \pm 9.39$ & 0.21 \\
\hline \multirow[t]{4}{*}{ G2 } & AET & $320 \pm 29.66$ & $315 \pm 25.09$ & 0.41 & $300 \pm 24.49$ & $290 \pm 17.51$ & 0.23 \\
\hline & ICT & $75 \pm 29.66$ & $74.16 \pm 20.10$ & 0.84 & $69.16 \pm 13.06$ & $70.8 \pm 22.45$ & 0.69 \\
\hline & AET/PEP & $0.286 \pm 0.04$ & $0.285 \pm 0.04$ & 0.53 & $0.286 \pm 0.03$ & $0.303 \pm 0.03$ & 0.24 \\
\hline & $\mathrm{HR}$ & $87.5 \pm 7.28$ & $84.8 \pm 5.07$ & 0.18 & $81.5 \pm 9.18$ & $80.6 \pm 7.42$ & 0.65 \\
\hline
\end{tabular}

D0: before treatment started; D42: after 42 days of the treatment; G1: group 1; G2: group 2; AET: aortic ejection time (ms); ICT: isovolumetric contraction time (ms); AET/PEP: relation between aortic ejection time and pre-ejection period; HR: heart rate (beats per minute).

\section{Clinical evaluation - G1 and G2}

HSS scores were similar in both groups, at all times (all $\mathrm{p}>0.05)$.

In G1, while on the daily regimen, the score was 5.5 before LT4 and 6.00 afterwards $(p>0.05)$. While on the weekly regimen, it was 5.75 before and 5.75 after LT4 ( $\mathrm{p}>0.05)$.

In $\mathrm{G} 2$, the score changed from 5.33 to 5.50 ( $\mathrm{p}>$ 0.05 ) while on the daily schedule, and from 5.5 to 5.33 on the weekly schedule $(\mathrm{p}>0.05)$.

\section{DISCUSSION}

Our study showed that treatment of hypothyroidism with weekly doses of LT4 leads to an increase in fT4 levels two and four hours after LT4, and a decrease in fT4 immediately before the weekly dose. In addition, weekly administration of LT4 did not cause significant alterations in the hyperthyroidism symptom scale and in echocardiographic parameters, either acutely or chronically.

It has been demonstrated that the use of weekly LT4 is scientifically plausible, but few studies have shown that the weekly administration of LT4 is well-tolerated and leads to normal levels of thyroid hormones. In a smaller randomized crossover study, Grebe and cols. showed that a weekly dose of LT4 was safe, and determined slightly higher levels of fT4 after LT4, and mild hypothyroidism before the following dose (16). In our study, no signs of hypothyroidism were obser- 
ved. Biochemically, mean levels of thyroid hormones were within normal range at all times. It is possible that the peripheral conversion of serum T4 to T3 was more efficient in our group of patients than in the patients evaluated by Grebe and cols. (16).

In another study, treatment with LT4 twice a week showed no statistically significant differences in thyroid hormones and in systolic time intervals, when compared to daily treatment (22), as observed in our study.

It is possible that weekly doses of LT4 determined some degree of subclinical hypothyroidism, reflected only on slightly elevated TSH, since its levels tended to be higher in patients taking weekly LT4, although not statistically different in comparison to patients taking LT4 daily.

As expected, a weekly dose of LT4, 7-fold higher than the usual dose, determined significantly higher T4 levels right after intake, but T3 levels did not change acutely, thus reinforcing the concept that deiodinase conversion of $\mathrm{T} 4$ to $\mathrm{T} 3$ is taking place. $\mathrm{T} 4$ changes in the absence of significant increases in TT3, therefore, have no clinical relevance (30-34). We chose to measure fT4 and T3 as early as 2 and 4 hours in order to identify their peak values, which occur 120 minutes after the LT4 administration (17).

In addition, the weekly administration of LT4 did not cause significant acute alterations in echocardiographic parameters, as shown in the comparison of the results of several echocardiographic parameters before and four hours after LT4. This is the first study to apply a more comprehensive analysis of heart function, by assessing the three different echocardiographic measures that are the most reliable reflection of cardiac parameters. We chose systolic intervals, which could be affected by transient hyperthyroidism (35). The lack of cardiac effect in this study strongly supports the hypothesis that the weekly administration of LT4 is a safe and practical manner of delivering LT4 replacement therapy. We chose to evaluate acute echocardiographic parameters because small acute fluctuations in thyroid hormones levels could lead to major cardiac repercussions. However, it is possible that changes in heart function could have been observed if the follow-up was longer.

We observed no significant clinical findings assessed by echocardiography and the HSS, thus reinforcing the role played by deiodinases in peripheral hormonal control. However, different results could have been observed if acute cardiovascular alterations were assessed by 24 -hour-eletrocardiographic monitoring, which can detect asymptomatic arrhythmia. Furthermore, we had a small sample size and a short follow-up. If we had evaluated a larger sample size, with a longer follow-up, tendencies might have become statistically significant.

A positive feature of our study lies on the fact that the crossover design allowed us to analyze results not only between groups, but also within the groups, comparing every patient with him/herself, thus minimizing possible confounding factors. In addition, it enabled us not only to evaluate the possible hyperthyroid effects immediately after the administration of weekly LT4, but also to assess any possible changes in thyroid hormones towards hypothyroidism.

In conclusion, a weekly dose of LT4 determines transient increases in fT4. Moreover, slight decreases in fT4 and TT3 may be observed seven days after LT4. More importantly, weekly doses of LT4 determined no acute changes in heart function or any symptoms. Treatment of hypothyroidism with a weekly dose of LT4 is an alternative for selected patients, and future studies should evaluate long-term outcomes.

Disclosure: Andressa Bornschein - none; Gilberto Paz-Filho none; Hans Graf - collaborator of the following laboratories: Merck-Serono, Abbott and Sanofi-Aventis; Gisah Amaral de Carvalho - Abbot and Sanofi-Aventis advisory Board; sponsored by Merck.

\section{REFERENCES}

1. Golden SH, Robinson KA, Saldanha I, Anton B, Ladenson PW. Clinical review: prevalence and incidence of endocrine and metabolic disorders in the United States: a comprehensive review. J Clin Endocrinol Metab. 2009;94(6):1853-78.

2. Roberts CG, Ladenson PW. Hypothyroidism. Lancet. 2004; 363(9411):793-803.

3. Bagattoli RM, Vaisman M, Lima JS, Ward LS. Estudo de adesão ao tratamento do hipotiroidismo. Arq Bras Endocrinol Metab. 2000;44(6):483-7.

4. Mandel SJ, Brent GA, Larsen PR. Levothyroxine therapy in patients with thyroid disease. Ann Intern Med. 1993;119(6):492-502.

5. Canaris GJ, Manowitz NR, Mayor GM, Ridgway EC. The Colorado thyroid disease prevalence study. Arch Intern Med. 2000;160(4):526-34.

6. Somwaru LL, Arnold AM, Joshi N, Fried LP, Cappola AR. High frequency of and factors associated with thyroid hormone over-replacement and under-replacement in men and women aged 65 and over. J Clin Endocrinol Metab. 2009;94(4):1342-5.

7. John-Kalarickal J, Pearlman G, Carlson HE. New medications which decrease levothyroxine absorption. Thyroid. 2007;17(8):763-5.

8. Wiersinga WM. Thyroid hormone replacement therapy. Horm Res. 2001;56(1):74-81.

9. Efstathiadou Z, Bitsis S, Milionis HJ, Kukuvitis A, Bairaktari ET, Elisaf MS, et al. Lipid profile in subclinical hypothyroidism: is L-thyroxine substitution beneficial? Eur J Endocrinol. 2001;145(6):705-10. 
10. Sharma R, SharmaTK, Kaushik GG, Sharma S, Vardey SK, Sinha $M$. Subclinical hypothyroidism and its association with cardiovascular risk factors. Clin Lab. 2011;57(9-10):719-24.

11. Biondi B, Palmieri EA, Lombardi G, Fazio S. Effects of subclinical thyroid dysfunction on the heart. Ann Intern Med. 2002;137(11):904.

12. Brent GA, Larsen PR, Davies TF. Hypothyroidism and thyroidites. In: Kronenberg HM, Melmed S, Polonsky KS, Larsen PR, editors. Williams Textbook of Endocrinology. 11th ed. Canada: Saunders; 2008. p. 377-409.

13. Watt $T$, Groenvold M, Rasmussen AK, Bonnema SJ, Hegedüs $L$, Bjorner JB, et al. Quality of life in patients with benign thyroid disorders. Eur J Endocrinol. 2006;154(4):501-10.

14. Bach-Huynh T, Nayak B, Loh J, Soldin S, Jonklaas J.Timing of levothyroxine administration affects serum thyrotropin concentration. J Clin Endocrinol Metab. 2009;94(10):3095-912.

15. Bernstein RS, Robbins J. Intermitent therapy with L-levothyroxine. N Engl J Med. 1969;281(26):1444-8.

16. Grebe SKG, Cooke RR, Ford HC, Fagerström JN, Cordwell DP, Lever NA, et al. Treatment of hypothyroidism with once weekly thyroxine. J Clin Endocrinol Metab. 1997;82(3):870-5.

17. Lips DJ, Van Reisen MT, Voigt V, Venekamp W. Diagnosis and treatment of levothyroxine pseudomalabsorption. Neth $\mathrm{J}$ Med. 2004;62(4):114-8.

18. Morris JC. How do you approach the problem ofTSH elevation in a patient on high-dose thyroid hormone replacement? Clin Endocrinol. 2009;70(5):671-3.

19. Rangan S, Tahrani AA, Macleod AF, Moulik PK. Once weekly thyroxine treatment as a strategy to treat non-compliance. Postgrad Med J. 2007;83(984):e3.

20. Sekadde CB, Slaunwhite WRJ, Aceto TJ, Murray K. Administration of thyroxine once a week. J Clin Endocrinol Metab. 1974;39(4):759-64.

21. Sethi MJ, Parr M, Bhatia B. Managenment strategies for hypothyroidism in non compliant patients: a case report and review of literature. S D Med. 2008;61(10):368-9.

22. Taylor J, Williams BO, Frater J, Stott DJ, Connell J. Twice-weekly dosing for thyroxine replacement in elderly patients with primary hypothyroidism. J Int Med Res. 1994;22(5):273-7.
23. Fish LH, Schwartz HL, Cavanaugh J, Steffes MW, Bantle JP, Oppenheimer JH. Replacement dose, metabolism, and bioavailability of levothyroxine in the treatment of hypothyroidism: role of triiodothyronine in pituitary feedback in humans. N Engl J Med. 1987;316(13):764-70.

24. Wallack MS, Adelberg HM, Nicoloff JT. A thyroid supression test using a single dose of L-thyroxine. N Engl J Med. 1970;283(8):402-5.

25. Rivkees SA, Hardin DS. Cretinism after weekly dosing with levothyroxine for treatment of congenital hypothyroidism. J Pediatr. 1994;125(1):147-9.

26. Banovac K, Papic M, Bilsker MS, Zakarija M, McKenzie JM. Evidence of hyperthyroidism in apparently euthyroid patients reated with levothyroxine. Ann Intern Med. 1989;149(4):809-12.

27. Klein I, Danzi S. Thyroid disease and the heart. Circulation. 2007;116(15):1725-35.

28. Klein I, Ojama K. Thyroid hormone and the cardiovascular system. N Engl J Med. 2001;344(7):501-9.

29. Klein I,Trzepacz PT, Roberts M, Levey GS. Symptom rating scale for assessing hyperthyroidism. Arch Intern Med. 1988;148(2):387-90.

30. Bianco AC, Salvatore D, Gereben B, Berry MJ, Larsen PR. Cellular and molecular biology, and physiological roles of the iodothyronine selenodeiodinases. Endocr Rev. 2002;23(1):38-89.

31. Gereben B, Zavacki AM, Ribich S, Kim BK, Huang SA, Simonides WS, et al. Cellular and molecular basis of deiodinase-regulated thyroid hormone signaling. Endocr Rev. 2008;29(7):898-938.

32. Kester MHA, Kuiper GGJM, Versteeg R, Visser TJ. Regulation of type III iodothyronine deiodinase expression in human cell lines. Endocrinology. 2006;147(12):5845-54.

33. Larsen PR. Type 2 iodothyronine deiodinase in human skeletal muscle: new insights into its physiological role and regulation. $J$ Clin Endocrinol Metab. 2007;94(6):1893-5.

34. Kohrle J. The deiodinase family: selenoenzymes regulating thyroid hormone availability and action. Cell Mol Life Sci. 2000;57(13-14):1853-63.

35. Tseng KH, Walfish PG, Persaud JA, Gilbert BW. Concurrent aortic and mitral valve echocardiography permits measurement of systolic time intervals as an index of peripheral tissue thyroid functional status. J Clin Endocrinol Metab. 1989;69(3):633-8. 